\title{
Safety and efficacy of current gentamicin dosing schedules used in neonates in Sri Lanka
}

\author{
*Thilanka Seneviratne ${ }^{1}$, Asanka Alexander ${ }^{2}$, Jeewani Gunawardhana ${ }^{1}$, Pathum Dissanayaka ${ }^{1}$, Chaminda \\ Liyanage $^{2}$, Nalika Menike ${ }^{3}$, Kosala Somaratne ${ }^{4}$
}

Sri Lanka Journal of Child Health, 2019; 48(1): 19-25

\begin{abstract}
Introduction: Gentamicin is the first line antibiotic for early onset neonatal sepsis. Yet the problem with gentamicin is the low therapeutic index. It is known that high trough levels correlate with ototoxicity and nephrotoxicity while the peak levels decide the therapeutic effect. Once daily dose (ODD) and twice daily dose (TDD) schedules are practised in neonatal units in Sri Lanka.
\end{abstract}

Objectives: To assess whether the ODD and TDD schedules of gentamicin used in neonates are effective in avoiding high serum trough levels and in achieving peak serum levels in the therapeutic range.

Method: A prospective study was conducted from April to August 2017 in four neonatal units on term neonates less than one week old, in whom gentamicin was started (TDD regime $=2.5 \mathrm{mg} / \mathrm{kg}$ 12 hourly and ODD regime $=5 \mathrm{mg} / \mathrm{kg} 24$ hourly) during the study period. Trough and peak serum gentamicin levels (SGLs) were assessed before and after the third dose in the TDD regime and after the second dose in the ODD regime. Serum creatinine ( $\mathrm{SCr})$ was measured in all the neonates and neonates with high trough levels were referred for hearing assessment.

Results: A total of 50 neonates of clinical maturity $37-41$ weeks and birth weight $1.8-4.1 \mathrm{~kg}$ was included. High trough levels $(>2 \mathrm{mg} / \mathrm{dl})$ were seen in $48 \%$ of the TDD group and in $12 \%$ of the ODD group $(p=0.005)$ Mean trough value in the ODD group was $1.15 \mathrm{mg} / \mathrm{dl}$ (SD 0.87) and in the TDD group was $2.14 \mathrm{mg} / \mathrm{dl}(\mathrm{SD} 1.72) .(\mathrm{T}=-2.564, \mathrm{df}=35$, $p=0.015)$. Peak SGL in the therapeutic range (5-

${ }^{1}$ Faculty of Medicine, Peradeniya, Sri Lanka, ${ }^{2}$ Provincial General Hospital, Badulla, Sri Lanka, ${ }^{3}$ Teaching Hospital, Kandy, Sri Lanka, ${ }^{4}$ Base Hospital, Rikillagaskada, Sri Lanka

*Correspondence: thilanka.medi@gmail.com (Received on 26 March 2018: Accepted after revision on 29 May 2018)

The authors declare that there are no conflicts of interest

Funding: University research grant for financial assistance.

Open Access Article published under the Creative

Commons Attribution CC-BY (c) (i)
$10 \mathrm{mg} / \mathrm{dl}$ ) was seen in $92 \%$ of ODD regime and in $80 \%$ of the TDD regime. Mean peak values in the ODD and TDD regimes were 9.42 (SD 2.37) $\mathrm{mg} / \mathrm{dl}$ and $7.12(\mathrm{SD} 2.18) \mathrm{mg} / \mathrm{dl}$ respectively $(\mathrm{T}=3.56$, $\mathrm{df}=48, p=0.001)$. $\mathrm{SCr}$ and the hearing assessment were within normal limits in all neonates.

Conclusions: The ODD gentamicin schedule of 5 $\mathrm{mg} / \mathrm{kg}$ achieves a significantly higher peak serum gentamicin level and safer trough levels than the TDD schedule of $2.5 \mathrm{mg} / \mathrm{kg}$.

DOI: http://dx.doi.org/10.4038/sljch.v48i1.8647

(Key words: Neonates, gentamicin, serum levels, trough levels, peak serum levels)

\section{Introduction}

Neonatal sepsis is a leading cause of morbidity and mortality among neonates especially in the developing countries ${ }^{1,2}$. Signs and symptoms of sepsis in a neonate can be non-specific and the progression can be rapid in comparison to older children $^{3}$. Hence, almost all newborn units adhere to the practice of having a very low threshold for starting empirical antibiotics the moment sepsis is clinically suspected ${ }^{4}$. The usual practice is to start two antibiotics with one covering the Gram positive agents and the other covering the Gram negative agents ${ }^{4,5}$. Aminoglycosides provide the Gram negative cover and gentamicin has been a first line aminoglycoside universally ${ }^{6}$.

Gentamicin is a fairly cheap agent and freely available in most units in countries with limited facilities $^{2}$. It has good synergistic activity when combined with ampicillin and certain bacteria continue to die even after the gentamicin level falls below the recommended trough levels ${ }^{7}$. Despite these advantages, gentamicin has its own demerits as well. The two most common side effects reported are nephrotoxicity and ototoxicity ${ }^{8}$. As all other aminoglycosides, gentamicin has a narrow therapeutic window and it is important to measure the gentamicin blood levels during treatment in order to assess whether the therapeutic concentrations are being achieved as well as toxicity is avoided as much as possible 9 .

When gentamicin levels are measured, two levels are used: the peak and the trough levels ${ }^{6}$. It has been found that the toxic effects are higher with 
high trough levels and the development of bacterial resistance to gentamicin can be minimized if the trough levels are kept as low as possible in between the doses ${ }^{7}$. The traditional dosing regimen for gentamicin comprise multiple dosing per day $(\mathrm{MDD})^{10}$. This can result in several unwanted effects. Fairly higher trough levels in this regimen due to shorter dose interval can increase the toxicity of the drug as well as encourage development of resistance ${ }^{5}$. It can also increase the potential errors due to complicated dosing intervals ${ }^{11}$. Meanwhile, recent studies have shown that once daily dosing (ODD) regimens show effective peak levels achieving bactericidal property while maintaining lower trough levels ${ }^{12}$. Therefore most units with advanced neonatal care settings adhere to ODD gentamicin regimens or even more extended dosing regimens for preterm infants ${ }^{5}$. Most studies on gentamicin blood level monitoring have been carried out in western countries and data from developing countries are limited. But even these limited data suggest that extended dosing regimen is more efficacious and less toxic compared to the MDD regimen ${ }^{13,14}$.

In Sri Lanka, gentamicin is used as the main aminoglycoside for neonatal sepsis and both MDD and ODD regimens are practised ${ }^{15}$. The MDD regimen is $2.5 \mathrm{mg} / \mathrm{kg}$ given 12 hourly while the ODD regimen comprises $5 \mathrm{mg} / \mathrm{kg}$ as a single daily dose $^{15}$. Although gentamicin is empirically used in neonatal units in Sri Lanka, two major areas for concern are evident. The first is that the gentamicin level in blood is not measured during therapy because that facility is not freely available in the state sector. This has resulted in gentamicin use being limited to term neonates or marginally preterm neonates. As serum gentamicin levels are unavailable, gentamicin is not used empirically in extreme premature neonates in many units. The second area of concern is that although both MDD and ODD regimens are being practised in different units, no local data are available to evaluate which regimen is better for the local set up. Up to now no study has been done regarding serum gentamicin level (SGL) monitoring in neonates in Sri Lanka. Available data from other countries may not be completely compatible with neonates nursed in local settings as the pharmacokinetic profile of the drug may vary between populations due to influences from genetic factors, lifestyle, drug interactions etc. Therefore this study was designed in order to monitor the gentamicin blood levels following the use of gentamicin in the local set up and see whether the data are compatible with those obtained from studies done in advanced neonatal care settings and also to determine whether the ODD regimen is better for the local setting in comparison to the traditional MDD regimen which is being used in certain neonatal units.

\section{Objectives}

To identify whether the ODD and TDD schedules of gentamicin used in neonates are effective in avoiding high serum trough levels and in achieving peak serum levels in the therapeutic range.

\section{Method}

The study was conducted for a period of six months from April to September 2017. Due to the difficulty of getting samples from neonates, the minimum sample size was calculated according to the method designed by SB Hulley and SR Cummings ${ }^{16}$. The calculated minimum sample size is 16 per dosing schedule. Sample size calculation was based on following assumptions

1. The width of the confidence level $=1$

2. Confidence interval $95 \%{ }^{17}$

We were able to include 25 patients for each dosing schedule.

Term neonates less than one week old in the neonatal units of Teaching Hospital Kandy, General Hospital Badulla, Base Hospital Mahiyanganaya and Base Hospital Diyathalawa in whom gentamicin was started during the period of study (April to September 2017) comprised the study group. Neonates of Teaching Hospital, Kandy were treated with the TDD regimen $(2.5 \mathrm{mg} / \mathrm{kg} 12$ hourly) and the ODD regimen $(5 \mathrm{mg} / \mathrm{kg} / 24$ hours) was given to the neonates of General Hospital Badulla, Base Hospital Mahiyanganaya and Base Hospital Diyathalawa.

Ethical clearance was obtained from the Ethical Review Committee of the Faculty of Medicine, University of Peradeniya. Written consent was taken from patient's mother or father. All staff at neonatal units were educated prior to data collection with the help of the Consultant Paediatricians in charge of the respective units. The patient selection and sample collection were done under the supervision of the registrars and consultants of the respective units. Data collection sheets were used to record the data which included the patient details, record on gentamicin dosage, frequency, times of administration and sample collection, concurrent administration of other drugs, results of septic screen, results of serum creatinine, as well as the contact information of the parents.

Two blood samples were collected from each patient, one hour prior to and one hour after the second gentamicin dose in the ODD schedule and one hour prior to and one hour after the third gentamicin dose in the TDD schedule according to the therapeutic drug monitoring guidelines for gentamicin in 'NICE guidelines' and British National Formulary for Children 2015) ${ }^{18,19}$. Samples taken one hour prior to gentamicin were used to measure the trough serum gentamicin levels 
and samples taken one hour after gentamicin were used to measure the peak gentamicin levels. $1.5 \mathrm{ml}$ of blood was collected into plain gel tubes. The centrifugation process was carried out at 3000rpm for 5 minutes to take serum. Serum separation was done in the laboratories of the respective hospitals and stored at $-4^{\circ} \mathrm{C}$ to $-8^{0} \mathrm{C}$, under the supervision of the respective chief medical laboratory technicians. Samples were transported weekly to the Department of Pharmacology (maintaining the cold chain) by one of the investigators via ambulance (when feasible). Samples were refrigerated at $-80^{\circ}$ $\mathrm{C}$ at the South Asian Clinical Toxicology Research Collaboration (SACTRC).

Analysis of serum gentamicin levels was carried out 2 weekly in accordance with the stability of samples and reagents. Analysis of serum gentamicin levels was done with immunoassay procedure and a CDX 90 fully automated drug analyser was used to analyse the samples. Two reagents were prepared before the test according to the method sheet. Before analysing the samples, two levels (high and low) of quality control were tested and the control values were monitored for any trends or shifts. If any trends or shifts were detected or if the control did not recover within the specified range, all operating parameters were reviewed to get precise results. Calibration was performed each day when the samples were assessed. Gentamicin assay was designed to quantitative measurement of the patient samples between $0.24 \mathrm{mg} / \mathrm{l}$ to $12 \mathrm{mg} / \mathrm{l}$. Specimen results greater than $12 \mathrm{mg} / \mathrm{l}$ were reported as $>12 \mathrm{mg} / \mathrm{l}$. Analysis was done at the laboratory at the Nephrology Unit, Kandy. Since there was a shortage of reagents, the latter samples were analysed at the Medical Research Institute. The same test procedure was used for the analysis of all the samples.

Serum creatinine ( $\mathrm{SCr}$ ) was measured in all from the same samples. Testing was done at the laboratory at Teaching Hospital Kandy. SCr was reassessed in neonates who had high serum trough levels at two months of age. All the patients with high serum gentamicin trough levels were referred for hearing assessment. This was done at two months of age at Teaching Hospital Kandy and Teaching hospital Badulla ENT Departments. Otoacoustic emissions were tested and 4 frequencies 5000, 4000, 3000 and $2000 \mathrm{~Hz}$ were measured. Analysis of serum gentamicin level (SGL) values and serum creatinine was done using the Chi square test and independent sample t-test, using SPSS.

\section{Results}

A total of 50 patients were included in the study. The demographic data of neonates in the ODD and TDD schedules are shown in Table 1.

Table 1: Demographic data of neonates in once and twice daily dosing schedules $(n=50)$

\begin{tabular}{|l|c|c|}
\hline \multicolumn{1}{|c|}{ Characteristic } & Once daily dosing schedule $(\boldsymbol{n}=\mathbf{2 5})$ & Twice daily dosing schedule $(\boldsymbol{n}=\mathbf{2 5})$ \\
\hline Gender & 15 & 18 \\
Male & 10 & 07 \\
Female & & \\
\hline Birth weight $(\mathrm{kg})$ & 01 & 00 \\
$<2.00$ & 03 & 02 \\
$2.00-2.49$ & 07 & 08 \\
$2.50-2.99$ & 10 & 09 \\
$3.00-3.49$ & 04 & 05 \\
$3.50-3.99$ & 00 & 01 \\
$>4.00$ & & \\
\hline Gestational age (weeks) & 06 & 07 \\
$37-37+6$ days & 05 & 07 \\
$38-38+6$ days & 09 & 07 \\
$39-39+6$ days & 05 & 04 \\
$>40$ & & \\
\hline
\end{tabular}

Clinical maturity of the neonates was within 37-41 weeks and the mean birth weight was $3.02( \pm 0.51)$ $\mathrm{kg}$.
The trough levels and peak serum levels of the neonates in the two dosing schedules of gentamicin are shown in Table 2 and Figures 1 and 2.

Table 2: Trough levels and peak serum levels of neonates in the two dosing schedules of gentamicin (n=50)

\begin{tabular}{|c|c|c|}
\hline Level of gentamicin & $\begin{array}{c}\text { Once daily dosing schedule }(n=25) \\
\text { Number }(\%)\end{array}$ & $\begin{array}{c}\text { Twice daily dosing schedule }(n=25) \\
\text { Number }(\%)\end{array}$ \\
\hline $\begin{array}{l}\text { Trough level } \\
\text { High }(>2 \mathrm{mg} / \mathrm{l}) \\
\text { Normal }(2 \mathrm{mg} / 1 \text { or }<)\end{array}$ & $\begin{array}{l}03(12) \\
22(88)\end{array}$ & $\begin{array}{l}12(48) \\
13(52)\end{array}$ \\
\hline $\begin{array}{l}\text { Peak serum level } \\
\text { Within therapeutic range } \\
\text { Not within therapeutic range }\end{array}$ & $\begin{array}{l}23(92) \\
02(08)\end{array}$ & $\begin{array}{l}20(80) \\
05(20)\end{array}$ \\
\hline
\end{tabular}


High trough levels of gentamicin were defined as more than $2 \mathrm{mg} / \mathrm{l}$. Peak serum levels of gentamicin within therapeutic range was defined as 5-10 $\mathrm{mg} / \mathrm{l}^{18,19}$. Number of neonates who had high and low trough levels in the two dosing schedules were analysed using Chi square test. Number of neonates who had peak serum levels in therapeutic range and sub therapeutic range in the two dosing schedules were also analysed using the Chi square test. Mean trough levels and mean peak levels in the two dosing schedules were tested using independent sample t-test.

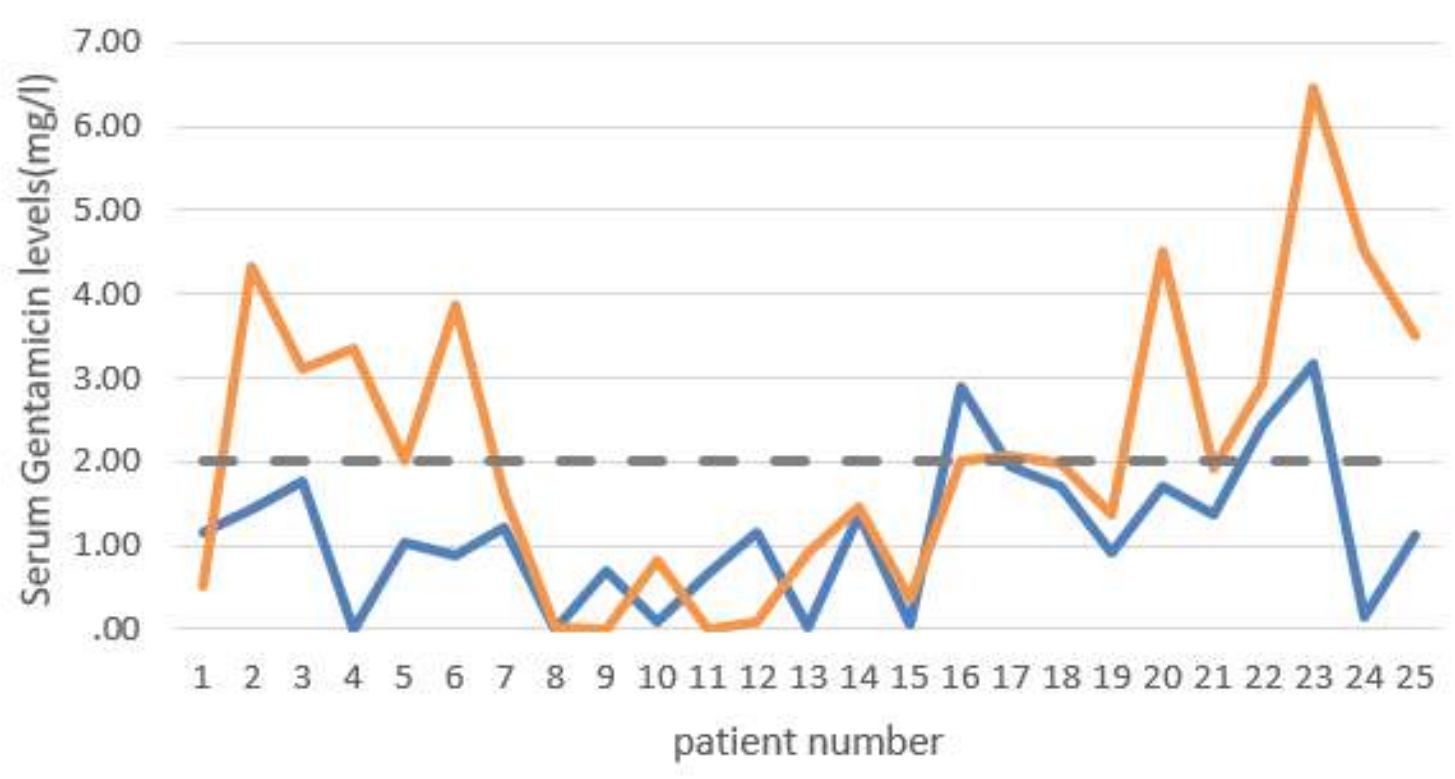

Once a Daily $\quad$ Twice a daily - Higher Margin of Trough Level

Figure 1: Trough levels of neonates in once daily and twice daily dosing schedules

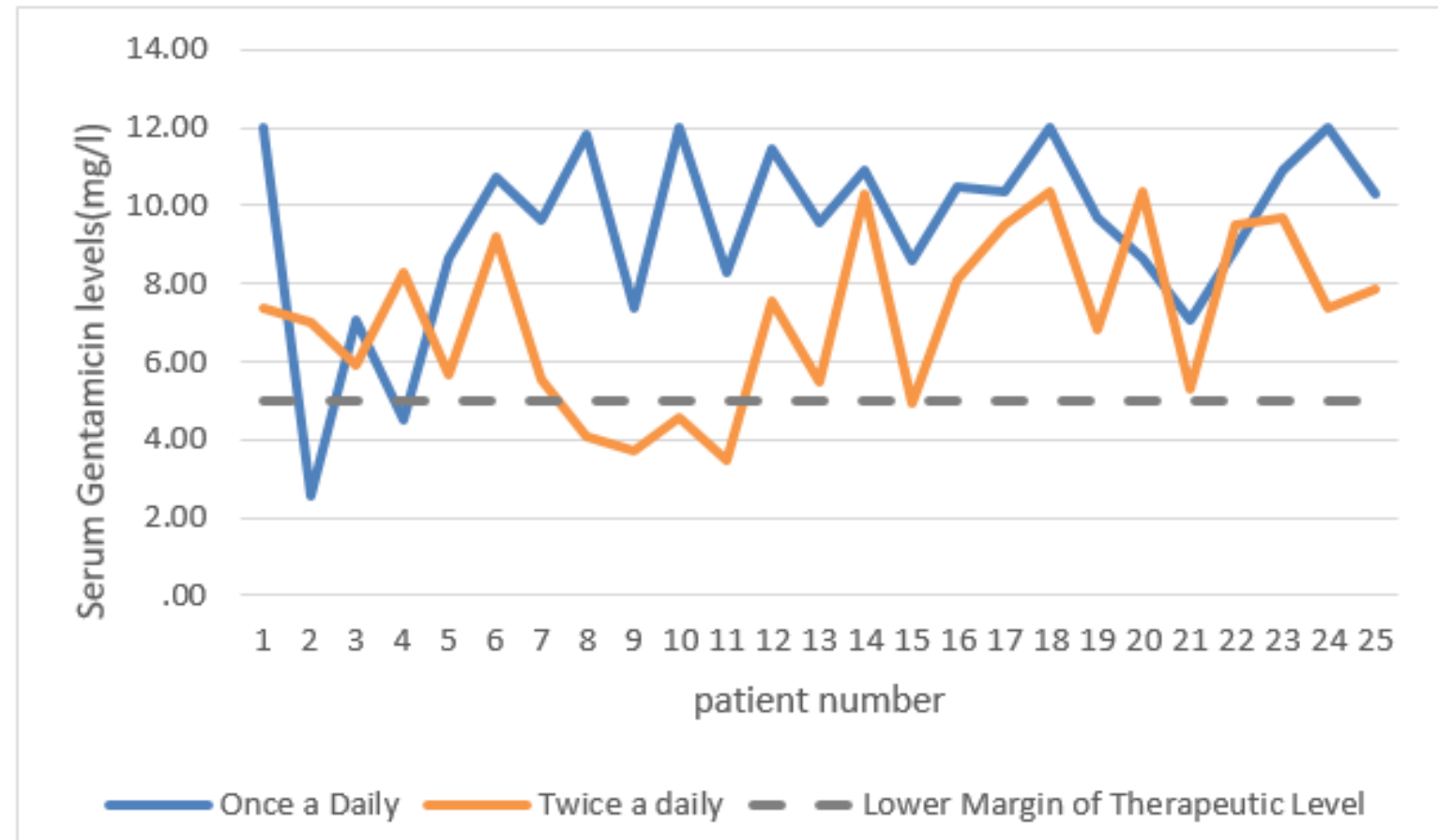

Figure 2: Peak serum levels of neonates in once daily and twice daily dosing schedules 
High trough levels $(>2 \mathrm{mg} / \mathrm{l})$ were seen in $48 \%$ of the TDD group and in $12 \%$ of the ODD group $(p=0.005)$. Mean trough values of the ODD group and the TDD group were $1.15 \mathrm{mg} / \mathrm{l}$ (SD 0.87) and $2.14 \mathrm{mg} / 1$ (SD 1.72) respectively $(\mathrm{T}=-2.564$, df $=35, p=0.015$ ).

Peak serum concentration in therapeutic range (5$10 \mathrm{mg} / \mathrm{l}$ ) was seen in $92 \%$ of the ODD regimen and in $80 \%$ of the TDD regimen $(p=0.417)$. Mean peak values in the ODD and TDD regimens were 9.42 (SD 2.37) $\mathrm{mg} / \mathrm{l}$ and 7.12 (SD 2.18) $\mathrm{mg} / \mathrm{l}(\mathrm{T}=3.56$, $\mathrm{df}=48, p=0.001)$.

$\mathrm{SCr}$ was assessed in all samples. Repeat $\mathrm{SCr}$ assessment was carried out in patients who had high trough levels. All creatinine levels were within normal limits. Hearing assessment was within normal limits in all neonates.

Mean SCr in ODD and TDD groups were 66.47 $( \pm 21.22)$ and $68.73( \pm 19.62) \mu \mathrm{mol} / 1$ respectively $(p=$ 0.711). Mean SCr in the neonates who had high and low trough levels were $71.89( \pm 18.73)$ and $65.66( \pm 20.91) \mu \mathrm{mol} / \mathrm{l}$ respectively $(p=0.344)$. Mean SC in neonates who had peak levels in therapeutic and sub therapeutic range were 66.66 $( \pm 18.97) \quad \mathrm{mg} / \mathrm{dl}$ and $74.84 \quad( \pm 30.83) \quad \mathrm{mg} / \mathrm{dl}$ respectively $(p=0.401)$. There was no significant correlation of $\mathrm{SCr}$ with the trough and peak SGL $(p=0.713)$

\section{Discussion}

The results of the current study are similar to those observed in studies performed in neonatal units with advanced settings. While a statistically significant proportion of neonates receiving the TDD schedule had serum gentamicin trough levels of more than $2 \mathrm{mg} / \mathrm{l}$ the neonates receiving the ODD regimen rarely had higher trough values. This finding is in par with many studies done previously in different settings ${ }^{6,20}$. Achieving a lower trough level is important in minimizing the potential renal and ototoxic effects of aminoglycosides. The current study reports almost $50 \%$ of neonates treated with the TDD regimen having trough levels higher than the recommended cut off level. Therefore, one in two neonates receiving the TDD regimen of gentamicin are at a risk of developing gentamicin associated adverse effects.

The neonates who had higher trough levels were evaluated for the presence of possible ototoxic and nephrotoxic effects but fortunately none of the neonates exhibited any adverse effects. Yet, it should be emphasized that the current study involved only a limited sample size of 50 neonates. A large scale study should be conducted to evaluate the potential side effects of gentamicin associated with the higher trough levels. In a country with limited facilities to measure and monitor gentamicin levels, it is a safe option to adopt an ODD regimen for gentamicin rather than TDD regimen as the former is better in avoiding higher trough levels.

While achieving a lower trough level, the ODD regimen was potent enough to achieve the recommended peak serum gentamicin level (SGL) which is needed for the bactericidal effects of aminoglycosides. A higher proportion of the neonates receiving the ODD regimen recorded recommended peak SGL in comparison with the neonates receiving the TDD regimen but a statistically significant difference was not seen. Studies involving a larger sample size have proven that ODD regimen is significantly effective in achieving peak SGL compared with the multiple daily dosing regimen ${ }^{10,20}$. However, the above findings are enough to confirm that the benefits of ODD gentamicin regimen which has been observed in previous studies are useful for the local set up as well.

Studies have been performed to evaluate the effectiveness of $4 \mathrm{mg} / \mathrm{kg}$ ODD regimen compared to $5 \mathrm{mg} / \mathrm{kg}$ ODD regimen ${ }^{21}$. This lower dose regimen can be studied in our local setting using the same protocol of this study as it will further reduce the risk of gentamicin toxicity while retaining the ability to achieve the recommended peak SGL. This could become a cost-effective regimen compared to the existing regimen as proven by past studies ${ }^{14,22}$.

One limitation of the study was that it involved neonates born at or above 37 weeks of gestation. A larger proportion of neonates receiving gentamicin in the neonatal units are premature neonates. A similar study needs to be carried out in the local setting to identify and evaluate the pharmacokinetic effects of gentamicin in preterm neonates comparing the different dosing regimens.

\section{Conclusions}

ODD gentamicin schedule of $5 \mathrm{mg} / \mathrm{kg}$ per dose achieves a significantly higher peak serum gentamicin level and safer trough levels than the TDD schedule of $2.5 \mathrm{mg} / \mathrm{kg}$ per dose.

\section{Acknowledgements}

The staff of the neonatal units and the laboratory staff of Teaching Hospital Kandy, Provincial General Hospital, Badulla and Base Hospitals Mahiyanganaya and Diyathalawa, Staff of ENT Department of Teaching Hospital Kandy and Provincial General Hospital Badulla are gratefully acknowledged. Head of the Department of Pharmacology and the laboratory staff of Medical Research Institute, Colombo, South Asian Clinical Toxicology Research Collaboration and Prof. P.V.R. Kumarasiri, Department of Community 
Medicine, Peradeniya are gratefully acknowledged for the invaluable support.

\section{References}

1. UNICEF Data. (2018). UNICEF statistics. [online] Available at: https://data.unicef.org

2. Musiime GM, Seale AC, Moxon SG et al. Risk of gentamicin toxicity in neonates treated for possible severe bacterial infection in low- and middleincome countries: Systematic Review. Tropical Medicine and International Health 2015; 20(12):1593-606.

https://doi.org/10.1111/tmi.12608

PMid: 26426298

3. Randolph AG, McCulloh RJ. Paediatric sepsis: Important considerations for diagnosing and managing severe infections in infants, children, and adolescents. Virulence 2014; 5(1):179-89. https://doi.org/10.4161/viru.27045

PMid: 24225404 PMCid: PMC3916372

4. Polin RA, Papile LA, Baley JE, et al. Management of neonates with suspected or proven early-onset bacterial sepsis. Pediatrics 2012; 129(5): 1006-15. https://doi.org/10.1542/peds.2012-0541 PMid: 22547779

5. Chattopadhyay B. Newborns and gentamicin--how much and how often? Journal of Antimicrobial Chemotherapy 2002; 49(1):13-6.

https://doi.org/10.1093/jac/49.1.13

PMid: 11751761

6. Thureen PJ, Reiter PD, Gresores A, Stolpman NM, Kawato K, Hall DM. Once- versus twice-daily gentamicin dosing in neonates $\geq 34$ weeks' gestation: Cost-effectiveness analyses. Pediatrics 1999; 103(3):594-8.

https://doi.org/10.1542/peds.103.3.594

PMid: 10049962

7. McLean AJ, Bastone EB, IoannidesDemos LL, Spicer W. Bactericidal effect of gentamicin trough concentration provides a rationale for administration of bolus doses and maintenance of trough levels. Antimicrobial Chemotherapy 1994; 13(5):999-1004.

https://doi.org/10.1093/jac/33.5.999
8. Kahlmeter G, Dahlager J. Aminoglycoside toxicity - a review of clinical studies published between 1975 and 1982 . Antimicrobial Chemotherapy 1984; 13(suppl. A):9-22. https://doi.org/10.1093/jac/13.suppl_A.9

9. Rao SC, Srinivasjois R, Moon K. One dose per day compared to multiple doses per day of gentamicin for treatment of suspected or proven sepsis in neonates. Cochrane Database of Systematic Reviews 2016 Issue 12. Art. No.: CD005091. https://doi.org/10.1002/14651858.CD0050 91.pub4

10. Miron D. Once daily dosing of gentamicin in infants and children. Pediatric Infectious Disease Journal 2001; 20(12):1169-73.

https://doi.org/10.1097/000064542001120 00-00016

PMid: 11740327

11. El-Chaar GM, Supaswud-Franks T, Venugopalan L, et al. Extended-interval gentamicin administration in neonates: A simplified approach. Journal of Perinatology 2016; 36(8): 660-65. https://doi.org/10.1038/jp.2016.37 PMid: 26986995

12. Nestaas E, Bangstad H, Sandvik L, Wathne K. Aminoglycoside extended interval dosing in neonates is safe and effective: a meta-analysis. Archives of Disease in Childhood Fetal and Neonatal Edition 2005; 90(4):F294-F300. https://doi.org/10.1136/adc.2004.056317 PMid: 15857879 PMCid: PMC1721925

13. Hossain MM, Chowdhury NA, Shirin M, Saha SK, Miller-Bell M, Edwards D, et al. Simplified dosing of gentamicin for treatment of sepsis in Bangladeshi neonates. Journal of Health, Population, and Nutrition 2009; 27(5):640-5.

PMid: 19902799 PMCid: PMC2928089

14. Darmstadt G, Hossain M, Jana A, Saha S, Choi Y, Sridhar S, et al. Determination of extended-interval gentamicin dosing for neonatal patients in developing countries. Pediatric Infectious Disease Journal 2007; 26(6):501-7. https://doi.org/10.1097/INF.0b013e31805 $9 \mathrm{c} 25 \mathrm{~b}$

PMid: 17529867 
15. Family Health Bureau, Sri Lanka. National guidelines for newborn care 2014. Available from http:// fhb.health.gov.lk/web/index.php?option... newborncare...newborn.

16. Hulley SB, Cummings SR. Designing Clinical Research. Baltimore: William \& Wilkins; 1988. p219.

17. Agarwal G, Rastogi A, Pyati S, Wilks A, Pildes RS. Comparison of once-daily versus twice-daily gentamicin dosing regimens in infants $\geq 2500 \mathrm{~g}$. Journal of Perinatology 2002; 22:268-74. https://doi.org/10.1038/sj.jp.7210704 PMid: 12032787

18. Neonatal infection (early onset): antibiotics for prevention and treatment. National Institute for Health and Care Excellence (NICE) Clinical guidelines 201updated 2017. Available from: https:www.nice.org.uk/guidance/cg14 9/chapter/guidance\#therapeutic-drugmonitoring-for-gentamicin
19. British National Formulary 2017-2018.

20. Hagen I, Øymar K. Pharmacological differences between once daily and twice daily gentamicin dosage in newborns with suspected sepsis. Pharmacy World and Science 2009; 31(1):18-23. https://doi.org/10.1007/s11096-008-9255$\mathrm{y}$ PMid: 18982422

21. Kiatchoosakun P, Kosalaraksa P, Jirapradiththa J, Taksaphan S, Tassniyom S. Once daily gentamicin dosing of 4 $\mathrm{mg} / \mathrm{kg} /$ dose in neonates. Journal of the Medical Association of Thailand 2005; 88(7): 934-8.

PMid: 16241022

22. Kosalaraksa P, Janthep P, Jirapradittha J, Taksaphan S, Kiatchoosakun P. Once versus twice daily dose of gentamicin in Thai neonates. Journal of the Medical Association of Thailand 2004; 87(4) 3726.

PMid: 15217172 